\title{
Life-threatening Infections in Medically Immunocompromised Patients
}

\author{
Hasan M. Al-Dorzi, MD ${ }^{a}$, Raymond Khan, MD $^{a}$, \\ Yaseen M. Arabi, MD ${ }^{\mathrm{b}, *}$
}

\section{KEYWORDS}

- Critical illness • Chronic kidney failure • Chronic obstructive pulmonary disease

- Diabetes mellitus • Heart failure

\section{KEY POINTS}

- Chronic illnesses, such as diabetes mellitus, chronic obstructive pulmonary disease, chronic kidney disease, cirrhosis, and heart failure, are often associated with immune abnormalities that make affected patients prone to specific life-threatening infections.

- Although encountered in patients without chronic illnesses, the presentation and prognosis of these infections are frequently different making physicians' awareness about them crucial for appropriate management.

- Further studies on the management of life-threatening infections in these patients are needed to understand their special characteristics and determine the specific diagnostic and therapeutic approaches.

\section{INTRODUCTION}

Life-threatening infections occur frequently in patients with chronic diseases, which are increasing by approximately $1.5 \%$ per year. ${ }^{1}$ A large cohort study $(n=192,980)$ found that $56 \%$ of patients with severe sepsis have at least one chronic comorbidity, with complicated diabetes mellitus (DM) present in 3.2\%, chronic obstructive pulmonary disease (COPD) in 12.3\%, chronic kidney disease (CKD) in 5.4\%, and chronic liver disease in 4.5\%. ${ }^{1}$ Although patients with these conditions do not have primary defects in the immune system, they often have various immune abnormalities that make them prone to specific infections. In this review, we describe the

Disclosures: All authors declare no conflicts of interest and do not have any direct financial interest in the subject matter or materials discussed in the article or with a company making a competing product.

a Intensive Care Department, College of Medicine, King Saud bin Abdulaziz University for Health Sciences, PO Box 22490, MC 1425, Riyadh 11426, Saudi Arabia; b Respiratory Services, Intensive Care Department, College of Medicine, King Saud bin Abdulaziz University for Health Sciences, PO Box 22490, MC 1425, Riyadh 11426, Saudi Arabia

* Corresponding author.

E-mail address: yaseenarabi@yahoo.com 
life-threatening infections that occur in patients with chronic medical diseases, namely DM, COPD, CKD, cirrhosis, and heart failure (HF), and discuss their management and reported outcomes.

\section{PATHOGENESIS}

Various changes in the innate, cell-medicated, and humoral immunity have been described in patients with these chronic medical conditions. Reduced neutrophil chemotaxis after stimulation ${ }^{2}$ and blunted inflammatory response to endotoxemia ${ }^{3}$ have been shown in DM and functional abnormalities of neutrophils, monocytes, dendritic cells, and lymphocytes ${ }^{4-6}$ in uremia. In cirrhosis, several abnormalities have been described, including reduced numbers and function of Kupffer cells, ${ }^{7}$ impaired phagocytotic function of neutrophils, ${ }^{8}$ and downregulation of proinflammatory cytokine production after lipopolysaccharide stimulation. ${ }^{9}$ In patients with $\mathrm{HF}$, natural killer cells have been shown to have decreased sensitivity to activation by interleukin (IL)-2 and interferon- $\gamma .^{10}$

Additionally, soft tissue breakage in DM and edema in cirrhosis and HF increase the risk of skin and soft tissue infections (SSTIs). Glucosuria promotes bacterial growth in the urinary tract. The presence of hemodialyis or peritoneal dialysis access may lead to bacterial invasion into the blood or peritoneal space. Injury to the respiratory epithelial cells, ciliary dysfunction, and corticosteroid therapy predispose patients with COPD to recurrent respiratory tract infections. In cirrhosis, translocation of bacteria into ascitic fluid leads to spontaneous bacterial peritonitis (SBP) and the presence of intrahepatic shunts predisposes to endotipsitis.

\section{LIFE-THREATENING INFECTIONS IN DIABETIC PATIENTS Epidemiology}

DM is a global health problem. In 2010, the prevalence of DM among adults was $6.4 \%$ worldwide, $10.3 \%$ in the United States and $9.2 \%$ in Canada. ${ }^{11}$ The prevalence was generally lower in Europe ${ }^{11}$ and higher in the Middle East. ${ }^{11}$ The worldwide DM prevalence is expected to increase to $7.7 \%$ by $2030 .{ }^{11}$ Studies from intensive care units (ICUs) have consistently shown higher DM prevalence than population-based studies, suggesting that DM predisposes to critical illness. DM prevalence among critically ill patients in the United States was $22.6 \%$ in the University Health System Consortium cohort $^{12}$ and $16.3 \%$ of the Mayo cohort. ${ }^{12}$ However, it was less prevalent $(7.2 \%)$ in a European cohort of critically ill patients with sepsis. ${ }^{13}$

DM is associated with increased risk of specific infections. In a 12-month prospective Dutch cohort study, which compared diabetic patients with hypertensive nondiabetic patients, DM was associated with increased risk of urinary tract infections (UTIs), SSTIs, and lower respiratory tract infections. ${ }^{14}$

\section{Specific Infections}

\section{UTIS}

UTIs are among the most common infections that affect diabetic patients and are often complicated. Emphysematous cystitis is a rare but serious complication of lower UTI and occurs mainly in individuals with DM. ${ }^{15}$ It most commonly occurs due to Escherichia coli, but other pathogens, including Enterobacter, Proteus, Klebsiella, and Candida species, have also been implicated. ${ }^{15}$ Emphysematous pyelonephritis almost exclusively occurs in patients with diabetes. It results from a severe form of acute multifocal bacterial nephritis. $E$ coli is the most commonly implicated pathogen, followed by other enteric gram-negative bacilli. ${ }^{15}$ 


\section{SSTIS}

A 2-year longitudinal prospective outpatient study showed that $9.1 \%$ of diabetic patients developed foot infections. ${ }^{16}$ SSTIs are composed of heterogeneous conditions, including simple cellulitis, infected foot ulcer with or without cellulitis, necrotizing fasciitis, deep abscesses, osteomyelitis, and septic arthritis. Causative pathogens vary depending on the condition. Among pathogens, $\beta$-hemolytic streptococci and Staphylococcus aureus predominate in cellulitis and acute infected foot ulcers. Methicillinresistant $S$ aureus (MRSA) prevalence has been increasing in infected foot ulcers. ${ }^{17} \mathrm{~A}$ multicenter study of hospitalized diabetic patients with SSTI and positive cultures showed that MRSA was the only isolate with a significantly increased prevalence from $11.6 \%$ to $21.9 \% .{ }^{17}$ Studies from India have also showed increasing prevalence of other multidrug-resistant gram-negative organisms. ${ }^{18,19}$ Gram-negative bacteria and anaerobes should be considered in chronic and deeper infections and polymicrobial infection should be considered in severe situations. ${ }^{20}$ Fournier gangrene represents a severe form of SSTI that involves the perineal, perianal, or genital regions, with $40 \%$ to $60 \%$ of patients having DM. ${ }^{21}$ Infecting microorganisms are usually mixed aerobic and anaerobic bacteria.

\section{Fungal infections}

$\mathrm{DM}$ is also a risk factor for fungal infections, including candidiasis and mucormycosis. A population-based surveillance for candidemia found that among diabetic adults, the average annual incidence of candidemia was 28 per 100,000 population. ${ }^{22}$ Approximately $50 \%$ of rhinocerebral mucormycosis cases occur in patients with DM. ${ }^{23}$

\section{Other infections}

DM also increases the morbidity associated with certain viral infections. DM has been associated with increased hospitalization and ICU admission after $\mathrm{H} 1 \mathrm{~N} 1$ infection. ${ }^{24}$

In the ICU, DM has been found to be a predictor of central line-associated bloodstream infections caused by gram-negative bacteria. ${ }^{25}$

\section{Antimicrobial Therapy}

Early and appropriate antimicrobial therapy has been shown to be associated with lower mortality in patients with severe sepsis and septic shock. ${ }^{26,27} \mathrm{DM}$ is considered a risk factor for infections with resistant microorganisms. Hence, empiric therapy is should be broad and directed against the suspected causative agents taking into consideration local susceptibility patterns.

\section{Surgical Indications and Therapy}

Current evidence suggests that the treatment of choice for emphysematous pyelonephritis is medical management combined with percutaneous drainage. ${ }^{28}$ However, nephrectomy may be needed in patients with extensive diffuse gas and renal destruction. ${ }^{28}$ Debridement and amputation may be necessary in diabetic foot ulcers with deep infection and gangrene. Necrotizing fasciitis and Fournier gangrene frequently require surgical intervention. Immediate debridement of necrotic tissues is one of the principles of treatment and the most important for improved survival. ${ }^{29}$ For mucormycosis, aggressive surgery and long-term therapy with amphotericin B may lead to improved outcomes. ${ }^{30}$

\section{Supportive Therapy}

Insulin therapy is essential in the management of infected diabetic patients with hyperglycemia. A meta-analysis of 29 randomized controlled trials totaling 8432 critically ill adult patients found that tight glucose control for diabetic and nondiabetic patients 
was associated with significantly decreased risk of septicemia. ${ }^{31}$ However, intensive insulin therapy has not been shown to reduce mortality in critically ill diabetic and nondiabetic patients. ${ }^{32}$

Agents used for reducing cardiovascular risk have been evaluated in infected diabetic patients. In a retrospective case-control study of 142,175 diabetic patients, van de Garde and colleagues $^{33}$ found that statin use was associated with reducing pneumonia risk.

\section{Outcome}

Certain DM-associated infections are known for their aggressive course and poor prognosis, especially if not treated promptly. Examples include Fournier gangrene and mucormycosis. DM is also associated with increased risk of death after H1N1 infection. ${ }^{34}$ In a prospective multicenter cohort study of invasive candidiasis, type 1 DM was independently associated with increased mortality. ${ }^{35}$ Analysis of 2 multicenter cohorts found that DM was associated with increased mortality risk within the first year after community-acquired pneumonia (CAP). ${ }^{36}$ Pittet and colleagues ${ }^{37}$ found that DM was significantly associated with increased mortality from septicemia in surgical ICU patients.

\section{LIFE-THREATENING INFECTIONS IN PATIENTS WITH COPD Epidemiology}

In 2011, the Centers for Disease Control and Prevention reported that $6.3 \%$ (15 million) of American adults had COPD, with prevalence increasing from $3.2 \%$ among people aged 18 to 44 years to more than $11.6 \%$ among those aged 65 years or older. ${ }^{38}$ The main causes of hospitalization are COPD exacerbation and cardiovascular disease. ${ }^{39,40}$

\section{Specific Infections}

\section{Acute exacerbation of COPD}

Even with therapy, patients with COPD have 1.4 acute exacerbations, on average, each year. ${ }^{41}$ Most COPD exacerbations are due to recurrent infections with viral or bacterial pathogens. Viruses may account for more than $50 \%$ of exacerbations. ${ }^{42} \mathrm{~A}$ meta-analysis of 8 studies found that picornavirus was the most commonly detected virus $(17.3 \%)$, followed by influenza $(7.4 \%)$, respiratory syncytial virus $(5.3 \%)$, corona viruses $(3.1 \%)$, and parainfluenza $(2.6 \%) .{ }^{43}$ Viral COPD exacerbations appear to be more severe and last longer than those without a viral trigger. ${ }^{44}$ Although bacteria frequently colonize the airways in COPD, bacterial exacerbations are usually associated with acquiring new bacterial strains of nontypeable Haemophilus influenzae, Streptococcus pneumoniae, Moraxella catarrhalis, and Pseudomonas aeruginosa. ${ }^{45}$

\section{CAP}

COPD course is frequently complicated by CAP. ${ }^{46}$ A cohort study of 40,414 patients with COPD aged 45 years or older found a CAP incidence rate of 22.4 per 1000 person-years. ${ }^{47}$ A population-based Spanish study of 1336 CAP cases and 1326 controls found that chronic bronchitis was present in $16.2 \%$ of cases versus $6.1 \%$ of controls and was an independent risk factor for CAP. ${ }^{48}$ The use of inhaled corticosteroids in patients with COPD has been implicated in the increased CAP risk as shown in a meta-analysis of 11 studies of combination preparations (fluticasone/salmeterol and budesonide/formoterol). ${ }^{49}$ When having CAP, patients with COPD usually present with more severe respiratory failure and higher Pneumonia Severity Index (PSI). ${ }^{50}$ 
$S$ pneumoniae is the most common isolated pathogen, followed by $H$ influenzae, $P$ aeruginosa, $S$ aureus, $M$ catarrhalis, and atypical pathogens. ${ }^{51,52}$ One study found that COPD was associated with increased pneumococcal bacteremia ${ }^{53}$ and another one found that Legionella pneumophila occurred predominantly in patients without COPD. ${ }^{51}$ Having repeated severe COPD exacerbations is a risk factor for CAP due to Pseudomonas species. ${ }^{54}$

COPD is also a risk factor for ventilator-associated pneumonia (VAP). ${ }^{55-57} P$ aeruginosa, Acinetobacter species, and $S$ aureus are the usual causative organisms. ${ }^{58,59}$ Systemic corticosteroid use increases the risk of infections with multidrug-resistant organisms. ${ }^{60}$

\section{Invasive pulmonary aspergillosis}

Patients with severe COPD who are receiving broad-spectrum antibiotics and corticosteroids have an increased incidence of invasive pulmonary aspergillosis (IPA). ${ }^{61,62}$ Guinea and colleagues ${ }^{61}$ found that Aspergillus was isolated from the lower respiratory tract of 16.3 patients per 1000 COPD admissions, but only $22.1 \%$ of them had probable IPA. IPA risk factors were ICU admission, receiving antibiotics in the prior 3 months, and accumulated corticosteroid doses (>700 mg) in the prior 3 months. ${ }^{61}$ A study of $96 \mathrm{ep}-$ isodes of severe hospital-acquired pneumonia at 2 Spanish ICUs found that 13 episodes were thought to be due to Aspergillus species (8 cases were classified as definite), most of which were in patients with COPD (84\%) and on steroids (69\%). ${ }^{63}$ One prospective study evaluated 55 consecutive patients with severe COPD, moderate to severe persistent bronchial asthma, or bronchiectasis who were admitted to a respiratory ICU in China and found that $13(23.6 \%)$ patients had IPA. ${ }^{62}$ Cumulative prednisone doses greater than $350 \mathrm{mg}$ before ICU admission was an independent risk factor. ${ }^{62}$

\section{Other infections}

Pneumocystis jiroveci causes opportunistic fungal respiratory tract infections in immunocompromised patients. However, it is a frequent colonizer of the lungs and was detected in the bronchoalveolar lavage of $20 \%$ of 169 immunocompetent patients in one study. ${ }^{64}$ Patients with COPD are at increased risk for Pneumocystis colonization. ${ }^{65,66}$ Infection with this organism should be considered in patients with COPD, especially those on corticosteroids or with nonresolving pneumonias.

Patients with COPD are at risk for influenza infections. Additionally, COPD was a risk factor for bacterial coinfection, as shown during the 2009 to 2010 influenza A H1N1 pandemic at 2 Spanish hospitals. ${ }^{67}$

\section{Antimicrobial Management}

Management of acute COPD exacerbation includes the administration of antibiotics, usually in the presence of increased sputum volume and purulence. A systematic review found that antibiotics significantly reduced the treatment failure risk, although the evidence was of low quality. ${ }^{68}$

The Infectious Diseases Society of America/American Thoracic Society has outlined evidence-based clinical practice guidelines for CAP management, which are stratified based on pneumonia severity. ${ }^{69}$ For non-ICU inpatients, a respiratory fluoroquinolone or $\beta$-lactam plus a macrolide are recommended. ${ }^{69}$ For ICU patients, a $\beta$-lactam (cefotaxime, ceftriaxone, or ampicillin-sulbactam) plus either azithromycin or a fluoroquinolone are recommended. When Pseudomonas risk exists, an antipneumococcal, antipseudomonal $\beta$-lactam (piperacillin-tazobactam, cefepime, imipenem, or meropenem) plus either ciprofloxacin, levofloxacin, or aminoglycoside are recommended. ${ }^{69}$ When MRSA risk exists, vancomycin or linezolid should be added. ${ }^{69}$ 
Voriconazole is the primary IPA treatment, as in a randomized trial that showed a survival benefit in patients with IPA who received voriconazole compared with amphotericin B. ${ }^{70}$ However, most of the enrolled patients had allogeneic hematopoietic-cell transplantation, acute leukemia, or other hematologic diseases. ${ }^{70}$ The use of combination therapy remains controversial with some evidence supporting combination antifungal therapy for salvage or failed monotherapy. ${ }^{71}$

Influenza is usually treated with the neuraminidase inhibitors, oseltamivir and zanamivir. For severe cases, it is recommended to increase oseltamivir dosage from $75 \mathrm{mg}$ to 150 mg twice daily. ${ }^{72}$ In 2009, the Food and Drug Administration approved the use of peramivir, an intravenous neuraminidase inhibitor, for the treatment of patients with severe influenza. ${ }^{73}$

\section{Supportive Care}

Systemic corticosteroids are used in acute COPD exacerbations, but their role in the management of patients with COPD with pneumonia is less defined. ${ }^{74}$ Hyperglycemia may develop and blood glucose control may be needed. Evaluation for adrenal insufficiency and corticosteroid replacement should be considered in severe COPD with frequent exacerbation and corticosteroid use.

There is emerging literature about the effect of cardioprotective medications in hospitalized patients with COPD exacerbation, including those with infection. Patients with COPD are at increased risk for specific cardiovascular conditions: arrhythmia, angina, acute myocardial infarction, $\mathrm{HF}$, stroke, and pulmonary embolism. ${ }^{40}$ One retrospective study of 825 patients hospitalized for COPD exacerbation found that $\beta$-blocker use was associated with reduced mortality. ${ }^{75}$ A nested case-control study found that more than 2 years of statin use was associated with $39 \%$ reduction in mortality risk in COPD. ${ }^{76} \mathrm{~A}$ retrospective cohort study of elderly patients hospitalized with COPD exacerbation, current statin use, and angiotensin-converting enzyme inhibitor/angiotensin receptor blocker use were significantly associated with decreased 90 -day mortality. ${ }^{77}$

\section{Outcomes}

Infections in patients with COPD are usually associated with significant morbidity and mortality. Acute COPD exacerbations requiring hospitalization are associated with a 30 -day all-cause mortality of $4 \%$ to $30 \% .{ }^{78}$ Mortality predictors include higher values of acute physiology scoring systems, low Glasgow Coma Scale on ICU admission, cardiac dysrhythmia, and length of hospital stay before ICU admission. ${ }^{79}$ The relationship between mortality and COPD in CAP is inconsistent with one study showing no increase in mortality risk, and other ones finding higher mortality, ${ }^{80}$ and other studies found increased mortality in hospitalized patients with COPD with CAP. ${ }^{52,81}$ In general, the mortality ascribed to CAP in this population is $4 \%$ to $34 \% .^{50-52,81}$ One prospective observational study of patients with VAP found COPD to be an independent predictor of ICU mortality. ${ }^{58}$ Another study of mechanically ventilated patients with COPD found that VAP was independently associated with ICU mortality. ${ }^{59}$ The mortality associated with IPA in patients with COPD is extremely high, reaching $91 \% .^{82}$

\section{LIFE-THREATENING INFECTIONS IN PATIENTS WITH CKD Epidemiology}

CKD is a global public health problem. In the United States, $9.6 \%$ of noninstitutionalized adults are estimated to have CKD. ${ }^{83}$ It is predicted that by 2015 there will be 136,166 patients with incident end-stage renal disease (ESRD) per year and 712,290 prevalent patients in the United States. ${ }^{84}$ 
Patients with CKD have high sepsis prevalence and severity. ${ }^{85,86}$ Evaluation of the ESRD program in the United States found that for new patients on hemodialysis, infection-related hospitalizations within the first year increased almost $100 \%$ from 1993 to 2005 , especially in the first 2 months. ${ }^{86}$ A study of 433 patients on hemodialysis found 2412 episodes of bacterial or fungal infections, with infection rate of 5.7 episodes per 1000 dialysis-days. ${ }^{87}$ Dialysis-related infections were responsible for $24 \%$ of the episodes, ${ }^{87}$ followed by below-the-knee SSTI (19\%), pneumonia (13\%), and other SSTIs (9\%). ${ }^{87}$ Most (82\%) infections were acquired in the community. ${ }^{87}$ Almost half (48\%) of cultured organisms were gram-positive cocci and $35 \%$ were aerobic gram-negative bacilli. ${ }^{87}$ Fifty percent of the total infection episodes occurred in the final year of life. ${ }^{87}$

\section{Specific Infections}

\section{Catheter-related bloodstream infections}

Central venous catheters are the most frequent vascular access for dialysis initiation among patients with incident ESRD. ${ }^{88}$ Incidence of catheter-related blood stream infection (CRBSI) ranges between 0.6 and 6.5 episodes per 1000 catheterdays. ${ }^{89-91} \mathrm{CRBSI}$ diagnosis is usually confirmed by isolation of the same microorganism from quantitative cultures of both the catheter and the peripheral blood in a septic patient without any other apparent source. Most CRBSI-causative agents are gram-positive organisms (52\%-64\%), most commonly $S$ aureus and Staphylococcus epidermidis. ${ }^{89,90}$

\section{Peritonitis}

Peritonitis is a complication of peritoneal dialysis (PD). One Australian study showed a peritonitis rate of 0.60 episodes per patient-year. ${ }^{92}$ Gram-positive organisms are the most common causative organisms, followed by gram-negative bacteria. ${ }^{92}$ Cultures can be polymicrobial and may be negative. ${ }^{92}$ Evaluation of 990 patients with incident PD from 1997 to 2009 identified 90 of them who required ICU admission and found that sepsis was the second (23\%) most common reason for ICU admission after cardiac problems, with peritonitis accounting for $69 \%$ of the sepsis admissions. ${ }^{93}$

\section{CAP}

Patients with CKD usually have more severe CAP, as reflected by higher PSI compared with other patients. ${ }^{94}$ The microbiology is similar to non-CKD, with $S$ pneumoniae being the most frequent pathogen. ${ }^{94}$

\section{Antimicrobial Therapy}

Empiric antimicrobial therapy for CRBSI should include broad-spectrum coverage for both gram-positive and gram-negative organisms. Owing to the high MRSA prevalence in the hemodialysis setting, empiric therapy should include anti-MRSA coverage $^{95}$ with deescalation when culture results become available. Antimicrobial therapy is usually administered for 7 to 14 days. ${ }^{96}$ The duration is extended to 4 to 6 weeks if there is persistent bacteremia or fungemia occurring more than 72 hours after hemodialysis catheter removal and for patients with endocarditis or suppurative thrombophlebitis and to 6 to 8 weeks for the treatment of osteomyelitis. ${ }^{96}$ The use of antibiotic catheter lock has been suggested to be instituted when catheter salvage is desired in the absence of exit site and tunnel infection. ${ }^{96}$ For the management of peritonitis associated with PD, a systematic review found similar primary response and relapse rate for intraperitoneal glycopeptide-based regimens compared with firstgeneration cephalosporin regimens. ${ }^{97}$ Nevertheless, glycopeptide-based regimens were more likely to achieve complete cure. ${ }^{97}$ The review also found that intraperitoneal 
antibiotics were superior to intravenous antibiotics in reducing treatment failure based on one study. ${ }^{97}$

\section{Surgical Indications and Therapy}

Patients with tunnel infection or port abscess require removal of the catheter, and incision and drainage if indicated. ${ }^{96}$ For CRBSI associated with tunneled hemodialysis access, the catheter should be surgically removed when any of the following conditions is present: severe complications (such as severe sepsis, endocarditis, and suppurative thrombophlebitis), persistent bacteremia or persistent clinical infection signs despite 48 to 72 hours of appropriate antimicrobial therapy, infection with $S$ aureus, $P$ aeruginosa, multidrug-resistant organisms, fungi, or mycobacetria. ${ }^{96}$ For patients on PD, surgical removal of the PD catheter should be performed in the presence of refractory peritonitis, defined as failure of the effluent to clear after 5 days of appropriate antibiotics. ${ }^{98}$

\section{Supportive Therapy}

Early arteriovenous fistula planning and institution may reduce access-related infections. A meta-analysis of 11 trials found that antibiotic catheter lock solutions significantly reduced CRBSI and catheter removal. ${ }^{99}$ As such, clinical practice guidelines recommended the prophylactic use of antimicrobial lock solution in patients with long-term catheters who have a history of multiple CRBSIs despite optimal maximal adherence to aseptic technique. ${ }^{100}$

Cardiovascular medications in patients with CKD have been studied in relationship to sepsis. A prospective multicenter cohort study of 1041 incident dialysis patients (1995-1998) with follow-up to 2005 found that sepsis-related hospitalizations were less frequent in patients receiving statins than in those not receiving statins. ${ }^{101}$

\section{Outcome}

A population-based study from the United States found that infections accounted for $20 \%$ of ESRD deaths, the second most after cardiovascular disease, and that sepsisrelated mortality in ESRD was approximately 100 -fold to 300 -fold higher compared with the general population. ${ }^{85}$ In a systematic review of 16 studies, comprising 6591 ICU admissions in which cardiovascular disease and sepsis accounted for most admissions, hospital mortality of patients with ESRD was high compared with matched patients with mild acute kidney injury. ${ }^{102}$ In a study of 619 patients with ESRD admitted to 11 Canadian ICUs mostly for sepsis, the mortality was $13.3 \%$ in the ICU and $38 \%$ and $48 \%$ at 6 and 12 months of follow-up. ${ }^{103}$ Among patients with CKD with CAP, mortality rates are markedly higher in dialysis patients compared with the general population ${ }^{104}$ and prior pneumococcal vaccination is associated with reduced mortality risk. ${ }^{94}$ In a retrospective study of 565 PD patients with infectious peritonitis, the mortality rate was $5.9 \%$ with peritonitis directly implicated in $15.2 \%$ of deaths and $68.5 \%$ of the infectious deaths. ${ }^{105}$ Another study of critically ill PD patients, with sepsis due to peritonitis as the most common admitting diagnosis, found a 1-year mortality of $53.3 \% .{ }^{93}$

\section{LIFE-THREATENING INFECTIONS IN PATIENTS WITH CIRRHOSIS Epidemiology}

In the United States, approximately $15 \%$ of the population has chronic liver disease, with cirrhosis being a major cause of death worldwide. Life-threatening infections are a major reason for admissions to the hospital and ICU. ${ }^{106-108}$ Cirrhosis-related infections are unique in terms of presentation, outcome, and therapeutic options. 


\section{Specific Infections}

Patients with cirrhosis may have a different presentation of infections compared with other patients. Studies have shown that up to one-third of patients with cirrhosis fail to develop leukocytosis or a temperature higher than $38^{\circ} \mathrm{C}$ or lower than $36^{\circ} \mathrm{C} .{ }^{109} \mathrm{~Pa}-$ tients with cirrhosis have lower baseline blood pressure, and higher heart rate and respiratory rate. ${ }^{110}$ Therefore, a complete workup, including a diagnostic paracentesis and ascitic fluid culture, urine and blood cultures, and chest radiograph, should be done soon when sepsis is suspected.

\section{Spontaneous bacterial peritonitis}

SBP is the most frequent infection in cirrhosis, accounting for $10 \%$ to $30 \%$ of all documented bacterial infections in hospitalized patients with cirrhosis. ${ }^{111-113}$ The European Association for the Study of the Liver (EASL) recommends that SBP diagnosis be based on neutrophil count in ascitic fluid of higher than $250 / \mathrm{mm}^{3} .{ }^{114}$ EASL defines bacterascites when an ascitic neutrophil count is lower than $250 / \mathrm{mm}^{3}$ but with a positive ascitic fluid culture and recommends antimicrobial therapy if the patient exhibits signs of systemic inflammation or infection. ${ }^{114}$

The most frequently isolated organisms in SBP are $E$ coli, Klebsiella species, and other Enterobacteriaceae. ${ }^{115}$ The microbiological etiology of SBP has changed in recent years. In particular, there is an upsurge in isolation in quinolone-resistant gram-negative bacteria (up to $30 \%$ ), ${ }^{111}$ extended-spectrum $\beta$-lactamase (from $7.9 \%-33 \%)^{116,117}$ and multidrug-resistant gram-positive bacteria. ${ }^{118} \mathrm{~A}$ recent study has shown an increase in Enterococcus species, $S$ aureus and Candida species, attributed to nosocomial infections and recent antibiotic treatment. ${ }^{119}$

\section{CAP}

Bacterial CAP is common in patients with cirrhosis. ${ }^{107,120}$ In fact, cirrhosis is a minor criterion in defining severe CAP. ${ }^{69}$ Compared with other patients, patients with cirrhosis more frequently presented with impaired consciousness, septic shock, higher PSI scores (classes IV-V) and bacteremia. ${ }^{121} S$ pneumoniae was the most common microorganism, followed by $H$ influenzae and $L$ pneumophila. ${ }^{121}$

\section{Skin and SSTIs}

SSTIs constitute approximately $11 \%$ of infections in patients with cirrhosis. ${ }^{122}$ These infections are caused by both gram-positive (S aureus and group A streptococci) and gram-negative bacteria (Klebsiella species, Aeromonas species, and Vibrio vulnificus). Cellulitis is the most frequently observed SSTI. Necrotizing fasciitis is less common ${ }^{123}$ and is predominantly caused by gram-negative bacilli. Necrotizing fasciitis from $V$ vulnificus, attributed to contaminated shellfish, has been reported in patients with cirrhosis. $^{124}$

\section{Community-acquired bacterial meningitis}

Community-acquired bacterial meningitis in patients with cirrhosis is an uncommon but a serious infection. In a Danish cohort study of 22,743 patients with cirrhosis, bacterial meningitis incidence was 54.4 per 100,000 person-years, and was highest in alcoholic cirrhosis, 65.3 per 100,000 person-years. ${ }^{125}$ Unfortunately, the diagnosis is often delayed. Su and colleagues ${ }^{126}$ showed that among 25 meningitis cases in patients with cirrhosis, meningitis was the initial tentative diagnosis in only 10 patients, whereas the other were given alternative diagnoses, such as hepatic encephalopathy, seizure, and alcohol withdrawal. In contrast, only 14 of the 192 patients without cirrhosis were labeled with alternative diagnoses. ${ }^{126}$ Patients with cirrhosis with meningitis presented with lower Glasgow Coma Scale and 
were more likely to have seizure and septic shock. Signs of meningeal irritation may be delayed or absent and mental status changes are often confused with hepatic encephalopathy. ${ }^{127}$

Data on microbiology are based on small series but show distinct pathogens. Su and colleagues ${ }^{126}$ showed that $K$ pneumoniae was responsible for 19 of 25 cases. Other cases were caused by Salmonella, Listeria monocytogenes, and $P$ aeruginosa. In another series of 29 cases, $E$ coli and $L$ monocytogenes were statistically more common in patients with cirrhosis than those without cirrhosis. ${ }^{128}$

\section{Endotipsitis}

Endotipsitis refers to transjugular intrahepatic portosystemic shunt (TIPS) infection. Its definition is still debated, but involves persistent bacteremia and fever together with either shunt occlusion, or vegetation, or bacteremia in the presence of a patent shunt, when other sources of bacteremia have been ruled out. ${ }^{129}$ Based on 4 small case series, endotipsitis incidence was approximately $1.5 \%$ (range 0.6\%-5.5\%). ${ }^{129}$ Patients present with fever and chills. ${ }^{129}$ Bacteremia can either occur early $(<120$ days) or late (>120 days) after stent insertion. ${ }^{129}$ The causative organisms were Enterobacteriaceae species (24\%), Enterococcus species (21\%), Staphylococcus species (18\%), Streptococcus species (9\%), anaerobic species (5\%), Lactobacillus species (5\%), fungal organisms (5\%), and other organisms in $14 \% .^{129}$

\section{Antimicrobial Management}

Empiric antibiotics should be started immediately following the diagnosis of SBP. Because the most common causative organisms of SBP are gram-negative aerobic bacteria, EASL recommended third-generation cephalosporins as the first-line antibiotic treatment with amoxicillin/clavulanic acid and quinolones as alternative options. ${ }^{114}$ However, quinolones are not recommended if they are used for SBP prophylaxis, in areas where there is a high prevalence of quinolone-resistance, or in nosocomial SBP. ${ }^{114}$ In nosocomial SBP, the incidence of ESBL-producing bacteria, as well as multidrug-resistant gram-positive bacteria such as Enterococcus faecium and MRSA, is increasing. ${ }^{130}$ Empiric therapy with carbapenems and glycopeptides is suggested in nosocomial infections in which there is high suspicion of multidrugresistant organisms, with deescalation as soon as possible.

The management of CAP in patients with cirrhosis follows the same guidelines outlined previously in the COPD section. Clinical practice guidelines of the Infectious Diseases Society of America ${ }^{131}$ and the European Federation of the Neurologic Societies $^{132}$ did not specifically address bacterial meningitis in patients with cirrhosis. Given the unique microbiology in this population, it is important for empiric antimicrobial therapy to cover $K$ pneumoniae, E coli, Listeria monocytogenes, and pneumococcus. SSTIs should be treated with broad-spectrum antimicrobials with timely surgical intervention for necrotizing fasciitis. The treatment of endotipsitis relies mainly on antimicrobial therapy because infected stent removal is impractical. Broadspectrum antibiotics to cover both gram-positive and gram-negative bacteria should be initiated. Vancomycin plus third-generation cephalosporins have been the most common regimen reported in some series. ${ }^{129}$ Carbapenems may be used if there is increased risk of multidrug-resistant organisms. If fungal infection is suspected, antifungal therapy should be started. ${ }^{129}$

In patients with cirrhosis presenting with septic shock, a recent multinational cohort study revealed that the use of inappropriate initial antimicrobials was related to increased mortality. Additionally, a single rather than 2 or more appropriate antimicrobials was also associated with higher mortality. ${ }^{120}$ 


\section{Supportive Therapy}

\section{Intravenous albumin}

A randomized, controlled study in SBP patients treated with cefotaxime showed that albumin significantly reduced mortality from $29 \%$ to $10 \%$ compared with cefotaxime alone. ${ }^{133}$ Awaiting further evidence, the EASL recommends that that all patients who develop SBP should be treated with broad-spectrum antibiotics and intravenous albumin. ${ }^{114}$

\section{Low-dose Hydrocortisone Therapy}

Relative adrenal insufficiency is very common (77\%) in patients with cirrhosis in septic shock. ${ }^{134}$ In a randomized controlled trial of 75 patients with cirrhosis presenting with septic shock, hydrocortisone therapy resulted in a significant hemodynamic improvement compared to placebo. ${ }^{134}$ However, there was no mortality benefit and hydrocortisone therapy was associated with increase shock relapse and gastrointestinal bleeding. ${ }^{134}$

\section{Granulocyte Colony-stimulating Factor}

A recent randomized controlled trial compared $5 \mu \mathrm{g} / \mathrm{kg}$ granulocyte colony-stimulating factor (G-CSF) with placebo in 47 patients with acute-on-chronic liver failure and found significant improvement of survival at day 60 (66\% vs $26 \%)$ and reduction in sepsis incidence. ${ }^{135}$ However, a recent meta-analysis of the use G-CSF in patients with severe sepsis and septic shock showed no benefit. ${ }^{136}$ Whether G-CSF has a special benefit in patients with cirrhosis remains unknown.

\section{Outcome}

Infections in patients with cirrhosis generally carry a poor prognosis. In-hospital mortality for the first episode of SBP ranges from $10 \%$ to $37 \%{ }^{113,137}$ and 1-year mortality has been reported to be $31 \%$ to $93 \% .{ }^{130}$ Similarly, CAP in cirrhosis is associated with $14 \%$ to $30 \%$ mortality. ${ }^{112,121}$ Factors associated with mortality include impaired consciousness, multilobar pneumonia, ascites, acute renal failure, bacteremia, ICU admission, and high Model For End-Stage Liver Disease score. ${ }^{121}$ Meningitis has a reported mortality of $38 \%$ to $63 \%$ in patients with cirrhosis. ${ }^{126,127}$ In patients with cirrhosis who develop septic shock, the mortality reaches $75.6 \% .{ }^{120}$ Further research in this important group of patients is needed with special focus on system-based interventions to improve the delivery of timely and appropriate management.

\section{LIFE-THREATENING INFECTIONS IN PATIENTS WITH HF Epidemiology}

An estimated 23 million people have HF worldwide ${ }^{138}$ including 5.7 million people in the United States alone. ${ }^{139}$ Patients with HF are at increased risk for CAP, a common reason for their hospitalization. ${ }^{48}$ Additionally, $\mathrm{HF}$ is a risk factor for admission of patients with CAP into the ICU. ${ }^{34}$ Patients with HF are at increased risk for influenza infection, including $\mathrm{H} 1 \mathrm{~N} 1$, as documented with the $2009 \mathrm{H} 1 \mathrm{~N} 1$ influenza infection. ${ }^{140}$

\section{Specific Infections}

The diagnostic approach to patients with severe CAP has been outlined earlier (COPD section). ${ }^{69}$ If viral pneumonia is suspected, respiratory samples for viral pathogens, including $\mathrm{H} 1 \mathrm{~N} 1$ polymerase chain reaction (PCR), should be obtained. CAP diagnosis in acute HF may be difficult because of similarity of the 2 conditions on physical 
examination and chest radiography. Serum B-type natriuretic peptide and $\mathrm{N}$-terminal pro-B-type natriuretic peptide may help to differentiate between these 2 entities in patients presenting with acute dyspnea. A recent trial in patients presenting to the emergency department with dyspnea found that a model using procalcitonin was more accurate than any other individual clinical variable for pneumonia diagnosis in all patients, and in those with acute HF. ${ }^{141}$ The study found that patients with acute HF and an elevated procalcitonin concentration $(>0.21 \mathrm{ng} / \mathrm{mL})$ had a worse outcome if not treated with antibiotics. ${ }^{141}$ Thoracic ultrasound demonstrating B-lines that suggests thickened interstitial or fluid-filled alveoli, seen most commonly in patients with HF, have been suggested to further aid in differentiating pneumonia from HF. ${ }^{142}$

\section{Antimicrobial Management}

Management of CAP in patients with HF follows the Infectious Diseases Society of America/American Thoracic Society consensus guidelines as summarized in the COPD section. ${ }^{69}$ Patients with suspected severe influenza, including $\mathrm{H} 1 \mathrm{~N} 1$, should be treated with oseltamivir as soon as possible.

\section{Outcome}

A population-based cohort study of adult patients hospitalized for pneumonia found a 30 -day mortality of $24.4 \%$ among patients with $\mathrm{HF}$ compared with $14.4 \%$ among other patients ${ }^{143}$ and that the severity of HF substantially increased mortality. ${ }^{143}$ Similarly, $\mathrm{HF}$ is independently associated with increased mortality risk in patients with $\mathrm{H} 1 \mathrm{~N} 1$ infections. $^{34}$

\section{SUMMARY}

Physicians who care for patients with life-threatening infections should know about the associated chronic illnesses, as these illnesses may affect immune function and predispose patients to specific infections that could be caused by multidrug-resistant or opportunistic organisms. This knowledge is crucial for proper care and management. Additionally, further prospective studies on the management of life-threatening infections in patients with DM, COPD, HF, CKD, or cirrhosis are needed to further understand the special characteristics and the specific diagnostic and therapeutic approaches.

\section{REFERENCES}

1. Angus DC, Linde-Zwirble WT, Lidicker J, et al. Epidemiology of severe sepsis in the United States: analysis of incidence, outcome, and associated costs of care. Crit Care Med 2001;29(7):1303-10.

2. Delamaire $M$, Maugendre $D$, Moreno $M$, et al. Impaired leucocyte functions in diabetic patients. Diabet Med 1997;14(1):29-34.

3. Andreasen AS, Pedersen-Skovsgaard T, Berg RM, et al. Type 2 diabetes mellitus is associated with impaired cytokine response and adhesion molecule expression in human endotoxemia. Intensive Care Med 2010;36(9):1548-55.

4. Ando M, Shibuya A, Yasuda M, et al. Impairment of innate cellular response to in vitro stimuli in patients on continuous ambulatory peritoneal dialysis. Nephrol Dial Transplant 2005;20(11):2497-503.

5. Lim WH, Kireta S, Leedham E, et al. Uremia impairs monocyte and monocytederived dendritic cell function in hemodialysis patients. Kidney Int 2007;72(9): 1138-48. 
6. Cendoroglo M, Jaber BL, Balakrishnan VS, et al. Neutrophil apoptosis and dysfunction in uremia. J Am Soc Nephrol 1999;10(1):93-100.

7. Rimola A, Soto R, Bory F, et al. Reticuloendothelial system phagocytic activity in cirrhosis and its relation to bacterial infections and prognosis. Hepatology 1984; 4(1):53-8.

8. Mookerjee RP, Stadlbauer V, Lidder S, et al. Neutrophil dysfunction in alcoholic hepatitis superimposed on cirrhosis is reversible and predicts the outcome. Hepatology 2007;46(3):831-40.

9. Xing T, Li L, Cao H, et al. Altered immune function of monocytes in different stages of patients with acute on chronic liver failure. Clin Exp Immunol 2007; 147(1):184-8.

10. Vredevoe DL, Moser DK, Gan XH, et al. Natural killer cell anergy to cytokine stimulants in a subgroup of patients with heart failure: relationship to norepinephrine. Neuroimmunomodulation 1995;2(1):16-24.

11. Shaw JE, Sicree RA, Zimmet PZ. Global estimates of the prevalence of diabetes for 2010 and 2030. Diabetes Res Clin Pract 2010;87(1):4-14.

12. Graham BB, Keniston A, Gajic $O$, et al. Diabetes mellitus does not adversely affect outcomes from a critical illness. Crit Care Med 2010;38(1):16-24.

13. Vincent JL, Preiser JC, Sprung CL, et al. Insulin-treated diabetes is not associated with increased mortality in critically ill patients. Crit Care 2010;14(1):R12.

14. Muller LM, Gorter KJ, Hak E, et al. Increased risk of common infections in patients with type 1 and type 2 diabetes mellitus. Clin Infect Dis 2005;41(3):281-8.

15. Patterson JE, Andriole VT. Bacterial urinary tract infections in diabetes. Infect Dis Clin North Am 1997;11(3):735-50.

16. Lavery LA, Armstrong DG, Wunderlich RP, et al. Risk factors for foot infections in individuals with diabetes. Diabetes Care 2006;29(6):1288-93.

17. Lipsky BA, Tabak YP, Johannes RS, et al. Skin and soft tissue infections in hospitalised patients with diabetes: culture isolates and risk factors associated with mortality, length of stay and cost. Diabetologia 2010;53(5):914-23.

18. Ramakant P, Verma AK, Misra R, et al. Changing microbiological profile of pathogenic bacteria in diabetic foot infections: time for a rethink on which empirical therapy to choose? Diabetologia 2011;54(1):58-64.

19. Gadepalli R, Dhawan B, Sreenivas V, et al. A clinico-microbiological study of diabetic foot ulcers in an Indian tertiary care hospital. Diabetes Care 2006;29(8): 1727-32.

20. Pellizzer G, Strazzabosco M, Presi S, et al. Deep tissue biopsy vs. superficial swab culture monitoring in the microbiological assessment of limb-threatening diabetic foot infection. Diabet Med 2001;18(10):822-7.

21. Sentochnik DE. Deep soft-tissue infections in diabetic patients. Infect Dis Clin North Am 1995;9(1):53-64.

22. Kao AS, Brandt ME, Pruitt WR, et al. The epidemiology of candidemia in two United States cities: results of a population-based active surveillance. Clin Infect Dis 1999;29(5):1164-70.

23. Joshi N, Caputo GM, Weitekamp MR, et al. Infections in patients with diabetes mellitus. N Engl J Med 1999;341(25):1906-12.

24. Allard R, Leclerc P, Tremblay $C$, et al. Diabetes and the severity of pandemic influenza A (H1N1) infection. Diabetes Care 2010;33(7):1491-3.

25. Sreeramoju PV, Tolentino J, Garcia-Houchins S, et al. Predictive factors for the development of central line-associated bloodstream infection due to gramnegative bacteria in intensive care unit patients after surgery. Infect Control Hosp Epidemiol 2008;29(1):51-6. 
26. Kumar A, Ellis $P$, Arabi $Y$, et al. Initiation of inappropriate antimicrobial therapy results in a fivefold reduction of survival in human septic shock. Chest 2009; 136(5):1237-48.

27. Kumar A, Roberts D, Wood KE, et al. Duration of hypotension before initiation of effective antimicrobial therapy is the critical determinant of survival in human septic shock. Crit Care Med 2006;34(6):1589-96.

28. Somani BK, Nabi G, Thorpe P, et al. Is percutaneous drainage the new gold standard in the management of emphysematous pyelonephritis? Evidence from a systematic review. J Urol 2008;179(5):1844-9.

29. Ustin JS, Malangoni MA. Necrotizing soft-tissue infections. Crit Care Med 2011; 39(9):2156-62.

30. Fairley C, Sullivan TJ, Bartley P, et al. Survival after rhino-orbital-cerebral mucormycosis in an immunocompetent patient. Ophthalmology 2000;107(3):555-8.

31. Wiener RS, Wiener DC, Larson RJ. Benefits and risks of tight glucose control in critically ill adults: a meta-analysis. J Am Med Assoc 2008;300(8):933-44.

32. Griesdale DE, de Souza RJ, van Dam RM, et al. Intensive insulin therapy and mortality among critically ill patients: a meta-analysis including NICE-SUGAR study data. CMAJ 2009;180(8):821-7.

33. van de Garde EM, Hak E, Souverein PC, et al. Statin treatment and reduced risk of pneumonia in patients with diabetes. Thorax 2006;61(11):957-61.

34. Hanslik T, Boelle PY, Flahault A. Preliminary estimation of risk factors for admission to intensive care units and for death in patients infected with $A(H 1 N 1) 2009$ influenza virus, France, 2009-2010. PLoS Curr 2010;2:RRN1150.

35. Leroy O, Gangneux JP, Montravers P, et al. Epidemiology, management, and risk factors for death of invasive Candida infections in critical care: a multicenter, prospective, observational study in France (2005-2006). Crit Care Med 2009; 37(5):1612-8.

36. Yende $\mathrm{S}$, van der Poll $\mathrm{T}$, Lee $\mathrm{M}$, et al. The influence of pre-existing diabetes mellitus on the host immune response and outcome of pneumonia: analysis of two multicentre cohort studies. Thorax 2010;65(10):870-7.

37. Pittet D, Thievent B, Wenzel RP, et al. Importance of pre-existing co-morbidities for prognosis of septicemia in critically ill patients. Intensive Care Med 1993; 19(5):265-72.

38. Centers for Disease Control and Prevention (CDC). Chronic obstructive pulmonary disease among adults-United States, 2011. MMWR Morb Mortal Wkly Rep 2012;23(61):938-43.

39. Holguin F, Folch E, Redd SC, et al. Comorbidity and mortality in COPD-related hospitalizations in the United States, 1979 to 2001. Chest 2005;128(4):2005-11.

40. Curkendall SM, DeLuise C, Jones JK, et al. Cardiovascular disease in patients with chronic obstructive pulmonary disease, Saskatchewan Canada cardiovascular disease in COPD patients. Ann Epidemiol 2006;16(1):63-70.

41. Aaron SD, Vandemheen KL, Fergusson D, et al. Tiotropium in combination with placebo, salmeterol, or fluticasone-salmeterol for treatment of chronic obstructive pulmonary disease: a randomized trial. Ann Intern Med 2007;146(8): 545-55.

42. Rohde G, Wiethege A, Borg I, et al. Respiratory viruses in exacerbations of chronic obstructive pulmonary disease requiring hospitalisation: a case-control study. Thorax 2003;58(1):37-42.

43. Mohan A, Chandra S, Agarwal D, et al. Prevalence of viral infection detected by PCR and RT-PCR in patients with acute exacerbation of COPD: a systematic review. Respirology 2010;15(3):536-42. 
44. Papi A, Bellettato CM, Braccioni F, et al. Infections and airway inflammation in chronic obstructive pulmonary disease severe exacerbations. Am J Respir Crit Care Med 2006;173(10):1114-21.

45. Sethi S, Evans N, Grant BJ, et al. New strains of bacteria and exacerbations of chronic obstructive pulmonary disease. N Engl J Med 2002;347(7): 465-71.

46. Chatila WM, Thomashow BM, Minai OA, et al. Comorbidities in chronic obstructive pulmonary disease. Proc Am Thorac Soc 2008;5(4):549-55.

47. Mullerova H, Chigbo C, Hagan GW, et al. The natural history of communityacquired pneumonia in COPD patients: a population database analysis. Respir Med 2012;106(8):1124-33.

48. Almirall J, Bolibar I, Serra-Prat M, et al. New evidence of risk factors for community-acquired pneumonia: a population-based study. Eur Respir J 2008;31(6):1274-84.

49. Nannini L, Cates CJ, Lasserson TJ, et al. Combined corticosteroid and longacting beta-agonist in one inhaler versus placebo for chronic obstructive pulmonary disease. Cochrane Database Syst Rev 2007;(4):CD003794.

50. Liapikou A, Polverino E, Ewig S, et al. Severity and outcomes of hospitalised community-acquired pneumonia in COPD patients. Eur Respir J 2012;39(4): 855-61.

51. Molinos L, Clemente MG, Miranda B, et al. Community-acquired pneumonia in patients with and without chronic obstructive pulmonary disease. J Infect 2009;58(6):417-24.

52. Rello J, Rodriguez A, Torres A, et al. Implications of COPD in patients admitted to the intensive care unit by community-acquired pneumonia. Eur Respir J 2006; 27(6):1210-6.

53. Marrie TJ. Bacteraemic pneumococcal pneumonia: a continuously evolving disease. J Infect 1992;24(3):247-55.

54. Arancibia F, Bauer TT, Ewig S, et al. Community-acquired pneumonia due to gram-negative bacteria and Pseudomonas aeruginosa: incidence, risk, and prognosis. Arch Intern Med 2002;162(16):1849-58.

55. Rello J, Ausina V, Ricart M, et al. Risk factors for infection by Pseudomonas aeruginosa in patients with ventilator-associated pneumonia. Intensive Care Med 1994;20(3):193-8.

56. Al-Dorzi HM, El-Saed A, Rishu AH, et al. The results of a 6-year epidemiologic surveillance for ventilator-associated pneumonia at a tertiary care intensive care unit in Saudi Arabia. Am J Infect Control 2012;40(9):794-9.

57. Celis R, Torres A, Gatell JM, et al. Nosocomial pneumonia. A multivariate analysis of risk and prognosis. Chest 1988;93(2):318-24.

58. Makris D, Desrousseaux B, Zakynthinos E, et al. The impact of COPD on ICU mortality in patients with ventilator-associated pneumonia. Respir Med 2011; 105(7):1022-9.

59. Nseir S, Di Pompeo C, Soubrier S, et al. Impact of ventilator-associated pneumonia on outcome in patients with COPD. Chest 2005;128(3):1650-6.

60. American Thoracic Society, Infectious Diseases Society of America. Guidelines for the management of adults with hospital-acquired, ventilator-associated, and healthcare-associated pneumonia. Am J Respir Crit Care Med 2005;171(4): 388-416.

61. Guinea J, Torres-Narbona M, Gijon P, et al. Pulmonary aspergillosis in patients with chronic obstructive pulmonary disease: incidence, risk factors, and outcome. Clin Microbiol Infect 2010;16(7):870-7. 
62. He H, Ding L, Li F, et al. Clinical features of invasive bronchial-pulmonary aspergillosis in critically ill patients with chronic obstructive respiratory diseases: a prospective study. Crit Care 2011;15(1):R5.

63. Valles J, Mesalles E, Mariscal D, et al. A 7-year study of severe hospitalacquired pneumonia requiring ICU admission. Intensive Care Med 2003; 29(11):1981-8.

64. Nevez G, Jounieaux V, Linas MD, et al. High frequency of Pneumocystis carinii sp.f. hominis colonization in HIV-negative patients. J Eukaryot Microbiol 1997; 44(6):36S.

65. Probst M, Ries $H$, Schmidt-Wieland $T$, et al. Detection of Pneumocystis carinii DNA in patients with chronic lung diseases. Eur $\mathrm{J}$ Clin Microbiol Infect Dis 2000;19(8):644-5.

66. Morris A, Sciurba FC, Lebedeva IP, et al. Association of chronic obstructive pulmonary disease severity and Pneumocystis colonization. Am J Respir Crit Care Med 2004;170(4):408-13.

67. Cilloniz C, Ewig S, Menendez R, et al. Bacterial co-infection with H1N1 infection in patients admitted with community acquired pneumonia. J Infect 2012;65(3): 223-30.

68. Vollenweider DJ, Jarrett $\mathrm{H}$, Steurer-Stey CA, et al. Antibiotics for exacerbations of chronic obstructive pulmonary disease. Cochrane Database Syst Rev 2012;(12):CD010257.

69. Mandell LA, Wunderink RG, Anzueto A, et al. Infectious Diseases Society of America/American Thoracic Society consensus guidelines on the management of community-acquired pneumonia in adults. Clin Infect Dis 2007;44(Suppl 2): S27-72.

70. Herbrecht R, Denning DW, Patterson TF, et al. Voriconazole versus amphotericin B for primary therapy of invasive aspergillosis. N Engl J Med 2002;347(6):408-15.

71. Singh N, Limaye AP, Forrest $\mathrm{G}$, et al. Combination of voriconazole and caspofungin as primary therapy for invasive aspergillosis in solid organ transplant recipients: a prospective, multicenter, observational study. Transplantation 2006; 81(3):320-6.

72. Rello J, Rodriguez A, Ibanez P, et al. Intensive care adult patients with severe respiratory failure caused by Influenza A (H1N1)v in Spain. Crit Care 2009; 13(5):R148.

73. Birnkrant D, Cox E. The emergency use authorization of peramivir for treatment of 2009 H1N1 influenza. N Engl J Med 2009;361(23):2204-7.

74. Confalonieri M, Urbino R, Potena A, et al. Hydrocortisone infusion for severe community-acquired pneumonia: a preliminary randomized study. Am J Respir Crit Care Med 2005;171(3):242-8.

75. Dransfield MT, Rowe SM, Johnson JE, et al. Use of beta blockers and the risk of death in hospitalised patients with acute exacerbations of COPD. Thorax 2008; 63(4):301-5.

76. Lahousse L, Loth DW, Joos GF, et al. Statins, systemic inflammation and risk of death in COPD: the Rotterdam study. Pulm Pharmacol Ther 2012;26:212-7.

77. Mortensen EM, Copeland LA, Pugh MJ, et al. Impact of statins and ACE inhibitors on mortality after COPD exacerbations. Respir Res 2009;10:45.

78. Donaldson GC, Wedzicha JA. COPD exacerbations. 1: epidemiology. Thorax 2006;61(2):164-8.

79. Messer B, Griffiths J, Baudouin SV. The prognostic variables predictive of mortality in patients with an exacerbation of COPD admitted to the ICU: an integrative review. QJM 2012;105(2):115-26. 
80. Fine MJ, Auble TE, Yealy DM, et al. A prediction rule to identify low-risk patients with community-acquired pneumonia. N Engl J Med 1997;336(4):243-50.

81. Restrepo MI, Mortensen EM, Pugh JA, et al. COPD is associated with increased mortality in patients with community-acquired pneumonia. Eur Respir J 2006; 28(2):346-51.

82. Samarakoon P, Soubani A. Invasive pulmonary aspergillosis in patients with COPD: a report of five cases and systematic review of the literature. Chron Respir Dis 2008;5(1):19-27.

83. Coresh J, Byrd-Holt D, Astor BC, et al. Chronic kidney disease awareness, prevalence, and trends among U.S. adults, 1999 to 2000. J Am Soc Nephrol 2005; 16(1):180-8.

84. Gilbertson DT, Liu J, Xue JL, et al. Projecting the number of patients with endstage renal disease in the United States to the year 2015. J Am Soc Nephrol 2005;16(12):3736-41.

85. Sarnak MJ, Jaber BL. Mortality caused by sepsis in patients with end-stage renal disease compared with the general population. Kidney Int 2000;58(4): 1758-64.

86. Collins AJ, Foley RN, Gilbertson DT, et al. The state of chronic kidney disease, ESRD, and morbidity and mortality in the first year of dialysis. Clin J Am Soc Nephrol 2009;4(Suppl 1):S5-11.

87. Berman SJ, Johnson EW, Nakatsu C, et al. Burden of infection in patients with end-stage renal disease requiring long-term dialysis. Clin Infect Dis 2004; 39(12):1747-53.

88. Astor BC, Eustace JA, Powe NR, et al. Type of vascular access and survival among incident hemodialysis patients: the Choices for Healthy Outcomes in Caring for ESRD (CHOICE) Study. J Am Soc Nephrol 2005;16(5):1449-55.

89. Tanriover B, Carlton D, Saddekni S, et al. Bacteremia associated with tunneled dialysis catheters: comparison of two treatment strategies. Kidney Int 2000; 57(5):2151-5.

90. Saad TF. Bacteremia associated with tunneled, cuffed hemodialysis catheters. Am J Kidney Dis 1999;34(6):1114-24.

91. Solomon LR, Cheesbrough JS, Ebah L, et al. A randomized double-blind controlled trial of taurolidine-citrate catheter locks for the prevention of bacteremia in patients treated with hemodialysis. Am J Kidney Dis 2010;55(6):1060-8.

92. Ghali JR, Bannister KM, Brown FG, et al. Microbiology and outcomes of peritonitis in Australian peritoneal dialysis patients. Perit Dial Int 2011;31(6):651-62.

93. Khan A, Rigatto $C$, Verrelli $M$, et al. High rates of mortality and technique failure in peritoneal dialysis patients after critical illness. Perit Dial Int 2012; 32(1):29-36.

94. Viasus D, Garcia-Vidal C, Cruzado JM, et al. Epidemiology, clinical features and outcomes of pneumonia in patients with chronic kidney disease. Nephrol Dial Transplant 2011;26(9):2899-906.

95. Stryjewski ME, Szczech LA, Benjamin DK Jr, et al. Use of vancomycin or firstgeneration cephalosporins for the treatment of hemodialysis-dependent patients with methicillin-susceptible Staphylococcus aureus bacteremia. Clin Infect Dis 2007;44(2):190-6.

96. Mermel LA, Allon M, Bouza E, et al. Clinical practice guidelines for the diagnosis and management of intravascular catheter-related infection: 2009 update by the Infectious Diseases Society of America. Clin Infect Dis 2009;49(1):1-45.

97. Wiggins KJ, Craig JC, Johnson DW, et al. Treatment for peritoneal dialysisassociated peritonitis. Cochrane Database Syst Rev 2008;(1):CD005284. 
98. Li PK, Szeto CC, Piraino B, et al. Peritoneal dialysis-related infections recommendations: 2010 update. Perit Dial Int 2010;30(4):393-423.

99. Yahav D, Rozen-Zvi B, Gafter-Gvili A, et al. Antimicrobial lock solutions for the prevention of infections associated with intravascular catheters in patients undergoing hemodialysis: systematic review and meta-analysis of randomized, controlled trials. Clin Infect Dis 2008;47(1):83-93.

100. O'Grady NP, Alexander M, Burns LA, et al. Summary of recommendations: guidelines for the Prevention of Intravascular Catheter-related Infections. Clin Infect Dis 2011;52(9):1087-99.

101. Gupta R, Plantinga LC, Fink NE, et al. Statin use and sepsis events [corrected] in patients with chronic kidney disease. J Am Med Assoc 2007;297(13): 1455-64.

102. Arulkumaran N, Annear NM, Singer M. Patients with end-stage renal disease admitted to the intensive care unit: systematic review. Br J Anaesth 2013;110: 13-20.

103. Sood MM, Miller L, Komenda P, et al. Long-term outcomes of end-stage renal disease patients admitted to the ICU. Nephrol Dial Transplant 2011;26(9): 2965-70.

104. Sarnak MJ, Jaber BL. Pulmonary infectious mortality among patients with endstage renal disease. Chest 2001;120(6):1883-7.

105. Perez Fontan M, Rodriguez-Carmona A, Garcia-Naveiro R, et al. Peritonitisrelated mortality in patients undergoing chronic peritoneal dialysis. Perit Dial Int 2005;25(3):274-84.

106. Arabi Y, Ahmed QA, Haddad S, et al. Outcome predictors of cirrhosis patients admitted to the intensive care unit. Eur J Gastroenterol Hepatol 2004;16(3): 333-9.

107. Borzio M, Salerno F, Piantoni L, et al. Bacterial infection in patients with advanced cirrhosis: a multicentre prospective study. Dig Liver Dis 2001;33(1): 41-8.

108. Cheruvattath R, Balan V. Infections in patients with end-stage liver disease. J Clin Gastroenterol 2007;41(4):403-11.

109. Rolando N, Harvey F, Brahm J, et al. Prospective study of bacterial infection in acute liver failure: an analysis of fifty patients. Hepatology 1990;11(1):49-53.

110. Canabal JM, Kramer DJ. Management of sepsis in patients with liver failure. Curr Opin Crit Care 2008;14(2):189-97.

111. Fernandez J, Navasa M, Gomez J, et al. Bacterial infections in cirrhosis: epidemiological changes with invasive procedures and norfloxacin prophylaxis. Hepatology 2002;35(1):140-8.

112. Caly WR, Strauss E. A prospective study of bacterial infections in patients with cirrhosis. J Hepatol 1993;18(3):353-8.

113. Pinzello G, Simonetti RG, Craxi A, et al. Spontaneous bacterial peritonitis: a prospective investigation in predominantly nonalcoholic cirrhotic patients. Hepatology 1983;3(4):545-9.

114. European Association for the Study of the Liver. EASL clinical practice guidelines on the management of ascites, spontaneous bacterial peritonitis, and hepatorenal syndrome in cirrhosis. J Hepatol 2010;53(3):397-417.

115. Wiest R, Garcia-Tsao G. Bacterial translocation (BT) in cirrhosis. Hepatology 2005;41(3):422-33.

116. Park $\mathrm{YH}$, Lee HC, Song HG, et al. Recent increase in antibiotic-resistant microorganisms in patients with spontaneous bacterial peritonitis adversely affects the clinical outcome in Korea. J Gastroenterol Hepatol 2003;18(8):927-33. 
117. Angeloni S, Leboffe C, Parente A, et al. Efficacy of current guidelines for the treatment of spontaneous bacterial peritonitis in the clinical practice. World $\mathrm{J}$ Gastroenterol 2008;14(17):2757-62.

118. Cholongitas E, Papatheodoridis GV, Lahanas A, et al. Increasing frequency of gram-positive bacteria in spontaneous bacterial peritonitis. Liver Int 2005; 25(1):57-61.

119. Reuken PA, Pletz MW, Baier M, et al. Emergence of spontaneous bacterial peritonitis due to enterococci-risk factors and outcome in a 12-year retrospective study. Aliment Pharmacol Ther 2012;35(10):1199-208.

120. Arabi YM, Dara SI, Memish Z, et al. Antimicrobial therapeutic determinants of outcomes from septic shock among patients with cirrhosis. Hepatology 2012; 56(6):2305-15.

121. Viasus D, Garcia-Vidal C, Castellote J, et al. Community-acquired pneumonia in patients with liver cirrhosis: clinical features, outcomes, and usefulness of severity scores. Medicine (Baltimore) 2011;90(2):110-8.

122. Rongey $\mathrm{C}$, Lim NH, Runyon BA. Cellulitis in patients with cirrhosis and edema: an under-recognized complication currently more common than spontaneous bacterial peritonitis. Open Gastroenterol J 2008;2:24-7.

123. Lee CC, Chi CH, Lee NY, et al. Necrotizing fasciitis in patients with liver cirrhosis: predominance of monomicrobial gram-negative bacillary infections. Diagn Microbiol Infect Dis 2008;62(2):219-25.

124. Muldrew KL, Miller RR, Kressin M, et al. Necrotizing fasciitis from Vibrio vulnificus in a patient with undiagnosed hepatitis and cirrhosis. J Clin Microbiol 2007; 45(3): 1058-62.

125. Molle I, Thulstrup AM, Svendsen N, et al. Risk and case fatality rate of meningitis in patients with liver cirrhosis. Scand J Infect Dis 2000;32(4): 407-10.

126. Su CM, Chang WN, Tsai NW, et al. Clinical features and outcome of communityacquired bacterial meningitis in adult patients with liver cirrhosis. Am J Med Sci 2010;340(6):452-6.

127. Pauwels A, Pines E, Abboura M, et al. Bacterial meningitis in cirrhosis: review of 16 cases. J Hepatol 1997;27(5):830-4.

128. Cabellos C, Viladrich PF, Ariza J, et al. Community-acquired bacterial meningitis in cirrhotic patients. Clin Microbiol Infect 2008;14(1):35-40.

129. Mizrahi M, Adar T, Shouval D, et al. Endotipsitis-persistent infection of transjugular intrahepatic portosystemic shunt: pathogenesis, clinical features and management. Liver Int 2010;30(2):175-83.

130. Wiest R, Krag A, Gerbes A. Spontaneous bacterial peritonitis: recent guidelines and beyond. Gut 2012;61(2):297-310.

131. Tunkel AR, Hartman BJ, Kaplan SL, et al. Practice guidelines for the management of bacterial meningitis. Clin Infect Dis 2004;39(9):1267-84.

132. Chaudhuri A, Martinez-Martin P, Kennedy PG, et al. EFNS guideline on the management of community-acquired bacterial meningitis: report of an EFNS Task Force on acute bacterial meningitis in older children and adults. Eur $\mathrm{J}$ Neurol 2008;15(7):649-59.

133. Sort P, Navasa M, Arroyo V, et al. Effect of intravenous albumin on renal impairment and mortality in patients with cirrhosis and spontaneous bacterial peritonitis. N Engl J Med 1999;341(6):403-9.

134. Arabi YM, Aljumah A, Dabbagh O, et al. Low-dose hydrocortisone in patients with cirrhosis and septic shock: a randomized controlled trial. CMAJ 2010; 182(18):1971-7. 
135. Garg V, Garg H, Khan A, et al. Granulocyte colony-stimulating factor mobilizes CD34(+) cells and improves survival of patients with acute-on-chronic liver failure. Gastroenterology 2012;142(3):505-512 e1.

136. Mohammad RA. Use of granulocyte colony-stimulating factor in patients with severe sepsis or septic shock. Am J Health Syst Pharm 2010;67(15):1238-45.

137. Nobre SR, Cabral JE, Gomes JJ, et al. In-hospital mortality in spontaneous bacterial peritonitis: a new predictive model. Eur J Gastroenterol Hepatol 2008; 20(12):1176-81.

138. McMurray JJ, Petrie MC, Murdoch DR, et al. Clinical epidemiology of heart failure: public and private health burden. Eur Heart J 1998;19(Suppl P):P9-16.

139. Roger VL, Go AS, Lloyd-Jones DM, et al. Heart disease and stroke statistics-2012 update: a report from the American Heart Association. Circulation 2012;125(1):e2-220.

140. Cui W, Zhao H, Lu X, et al. Factors associated with death in hospitalized pneumonia patients with 2009 H1N1 influenza in Shenyang, China. BMC Infect Dis 2010;10:145.

141. Maisel A, Neath SX, Landsberg J, et al. Use of procalcitonin for the diagnosis of pneumonia in patients presenting with a chief complaint of dyspnoea: results from the BACH (Biomarkers in Acute Heart Failure) trial. Eur J Heart Fail 2012; 14(3):278-86.

142. Liteplo AS, Marill KA, Villen T, et al. Emergency thoracic ultrasound in the differentiation of the etiology of shortness of breath (ETUDES): sonographic B-lines and $\mathrm{N}$-terminal pro-brain-type natriuretic peptide in diagnosing congestive heart failure. Acad Emerg Med 2009;16(3):201-10.

143. Thomsen RW, Kasatpibal N, Riis A, et al. The impact of pre-existing heart failure on pneumonia prognosis: population-based cohort study. J Gen Intern Med 2008;23(9):1407-13. 